\title{
Effect of simvastatin on MMPs and TIMPs in cigarette smoke-induced rat COPD model
}

\author{
This article was published in the following Dove Press journal: \\ International Journal of COPD \\ 22 February 2017 \\ Number of times this article has been viewed
}

Jiawei Sun ${ }^{1, *}$
Jie Bao ${ }^{2, *}$
Yanan Shi ${ }^{3}$
Bin Zhang
Lindong Yuan'
Junhong Li'
Lihai Zhang'
Mo Sun
Ling Zhang
Ling
Wuzhuang Sun'
'Department of Respiratory
Medicine, First Hospital of Hebei
Medical University, ${ }^{2}$ Department
of Respiratory Medicine, Chest
Hospital of Hebei Province, ${ }^{3}$ Maternal
and Child Health Care Center of
Hebei Province, ${ }^{4}$ Department of
Emergency, First Hospital of Hebei
Medical University, Shijiazhuang,
${ }^{5}$ Department of Respiratory Medicine,
People's Hospital of Liaocheng,
Liaocheng, ${ }^{6}$ Hebei Medical University,
Shijiazhuang, People's Republic of
China
*These authors contributed equally
to this work
to this work
Background: Proteases may play an important role in the development of chronic obstructive pulmonary disease and emphysema in response to cigarette smoke exposure (CSE). The current study was designed to investigate the expression of matrix metalloproteinase (MMP)-8, MMP-9, MMP-12, tissue inhibitor of MMP (TIMP)-1, and TIMP-4 in rat lung tissues in response to CSE, and assessed the effect of simvastatin in regulating expression of MMPs and TIMPs.

Methods: Thirty normal Sprague Dawley (SD) rats were divided into control $(n=10)$, CSE $(n=10)$, and CSE plus simvastatin $(n=10)$ groups. Animals were whole-body exposed to the cigarette smoke in the box for 1 hour each time, twice a day, 5 days a week for 16 weeks. Animals of CSE + simvastatin group were intra-gastrically administered simvastatin at a dose of $5 \mathrm{mg} / \mathrm{kg} /$ day followed by CSE. Bronchoalveolar lavage fluid was harvested for inflammatory cell count and lung tissues were stained for morphologic examination. Expression of mRNA and protein level of MMP-8, MMP-9, MMP-12, TIMP-1, and TIMP-4 was assessed by real-time reverse transcription polymerase chain reaction and immunohistochemistry, respectively.

Results: CSE resulted in a significant increase of mean linear intercept (MLI: 34.6 $\pm 2.0 \mu \mathrm{m}$ ) and bronchial wall thickness and diameter (BWT/D, 0.250 \pm 0.062$)$ compared to control (MLI: $24.0 \pm 1.7 \mu \mathrm{m}, \mathrm{BWT} / \mathrm{D}: 0.160 \pm 0.034, P<0.01$ ). In contrast, mean alveolar number was significantly decreased in the CSE group than that in the control group (13.5 \pm 2.0 of CSE vs $21.5 \pm 2.0 \mathrm{~N} / \mu \mathrm{m}^{2}$ of control, $P>0.01$ ). Simvastatin slightly but not significantly prevented alteration of MLI, BWT/D, and mean alveolar number (MLI: $33.4 \pm 1.4 \mu \mathrm{m}$; BWT/D: $0.220 \pm 0.052$; mean alveolar number: $15.5 \pm 2.5 \mathrm{~N} / \mu \mathrm{m}^{2}, P>0.05$ ). Total white blood cell was significantly increased in the bronchoalveolar lavage fluid of smoking group $\left(3.3 \pm 2.5 \times 10^{9}\right.$ cells $/ \mathrm{L}$ vs $1.1 \pm 1.3 \times 10^{9}$ cells $/ \mathrm{L}$ of control, $P<0.01$ ), and it was significantly reduced by simvastatin $\left(2.3 \pm 2.1 \times 10^{9}\right.$ cells $\left./ \mathrm{L}, P<0.01\right)$. CSE resulted in significantly increased accumulation of neutrophils and macrophages (neutrophils: $14.5 \% \pm 1.3 \%$ of CSE group vs $9.1 \% \pm 1.5 \%$ of control; macrophage: $91 \% \pm 3 \%$ of CSE group vs $87 \% \pm 2 \%$ of control, $P<0.05$ ), and simvastatin significantly reduced neutrophils $(12.9 \% \pm 2.0 \%, P<0.05)$ in the bronchoalveolar lavage fluid, but had no effect on macrophage $(89 \% \pm 1.6 \%, P>0.05)$. In response to CSE, MMP-8, MMP-9, and MMP-12 mRNA were upregulated more than sevenfold, while TIMP-1 and TIMP-4 increased two- to fivefold. Simvastatin significantly blocked upregulation of MMP-8 and -9 $(P<0.01)$, but had no effect on MMP-12, TIMP-1 and TIMP-4 mRNA $(P>0.05)$. In addition, simvastatin significantly blocked cigarette smoke-induced MMP-8 and -9 protein synthesis, while it had no significant effect on TIMP-1 and -4 protein synthesis even in the presence of cigarette smoke.

Conclusion: CSE resulted in imbalance of MMPs and TIMPs, and by which mechanism, cigarette smoke may lead to insufficient lung tissue repair. Simvastatin partially blocked airway inflammation and MMP production and, thus, statins may modulate composition of the lung extracellular matrix.

Keywords: tissue injury, tissue repair, smoking submit your manuscript | www.dovepress.com

Dovepress if in 1
International Journal of COPD 2017:12 717-724

(c) (i) (5) 2017 Sun et al. This work is published and licensed by Dove Medical Press Limited. The full terms of this license are available at https://www.dovepress.com/terms.php (c) ${ }_{\mathrm{BY}} \mathrm{NC}$ and incorporate the Creative Commons Attribution - Non Commercial (unported, v3.0) License (http://(creativecommons.org/licenses/by-nc/3.0/). By accessing the work you hereby accept the Terms. Non-commercial uses of the work are permitted without any further permission from Dove Medical Press Limited, provided the work is properly attributed. For permission hereby accept the Terms. Non-commercial uses of the work are permitted without any further permission from Dove Medians
for commercial use of this work, please see paragraphs 4.2 and 5 of our Terms (https://www.dovepress.com/terms.php). 


\section{Introduction}

Chronic obstructive pulmonary disease (COPD) is the third leading cause of death worldwide. ${ }^{1}$ COPD is characterized by chronic airway inflammation and irreversible airflow obstruction, which could result from abnormal airway tissue injury and remodeling. In this regard, the balance between extracellular matrix production and its destruction may be important in determining the outcomes of tissue repair. In particular, balanced and sufficient airway tissue repair is required to restore architectural integrity and normal function of airflow following injury. Insufficient repair may lead to emphysema and, in contrast, excessive repair or remodeling may lead to lung fibrosis. ${ }^{2}$

Cigarette smoke contains over a 1,000 chemicals. COPD-like airway injury and remodeling are developed in the rodent animals, such as rat and mouse, when they are chronically exposed to cigarette smoke., ${ }^{3,4}$ One of the potential mechanisms of the cigarette smoke-induced COPD is that cigarette smoke leads to insufficient lung tissue repair through altering production of matrix metalloproteinases (MMPs) and their biological inhibitors, tissue inhibitors of MMPs (TIMPs). ${ }^{5}$ The MMPs are a large family of proteolytic enzymes ${ }^{6}$ that are produced by both inflammatory cells and lung structural cells, including epithelial cells and fibroblasts. ${ }^{7,8}$

Currently, therapy of COPD and emphysema can partially alleviate symptoms, but has relatively little impact on the proteolytic destruction of lung structure. ${ }^{2}$ Novel therapeutic strategies that potentially block proteolytic tissue destruction, therefore, are of interest as possible approaches to alter the long-term natural history of COPD. In this regard, it has been reported that statins may be associated with reduced acute events and mortality of COPD. ${ }^{9,10}$

Statins are a class of cholesterol-lowering drugs that inhibit 3-hydroxy-3-methylglutaryl co-enzyme A. Recently, it has been reported that statins have anti-inflammatory and antioxidant effects, ${ }^{11}$ an inhibitory effect on MMP release from macrophages, lung fibroblasts, and vascular cells, ${ }^{7,12,13}$ as well as in the animal model of COPD in response to cigarette smoke exposure (CSE). ${ }^{5}$ Through the effect on MMPs, statins may directly regulate balance of MMPs and their biological inhibitors, TIMPs, and thereby, may modify the alterations in lung structure that compromise lung function.

The current study was designed to extend previous studies of simvastatin regulation on chronic airway inflammation and lung structural alteration in response to CSE. To investigate this, rats were exposed to cigarette smoke for 4 months with or without simvastatin treatment. Animals were sacrificed and alteration of lung structure was assessed by mean linear intercept (MLI), mean alveolar number (MAN), and bronchial wall thickness and diameter (BWT/D). Total and differential inflammatory cell counts in bronchoalveolar lavage fluid (BALF) were performed. Expression of mRNA and protein level of MMP-8, MMP-9, MMP-12, TIMP-1, and TIMP-4 were carried out by real-time reverse transcription polymerase chain reaction (RT-PCR) and immunohistochemistry, respectively.

\section{Materials and methods Animals and CSE}

Healthy male Sprague Dawley (SD) rats, 6 weeks old, body weight $110 \pm 20 \mathrm{~g}$, were maintained in the animal facilities at the Hebei Medical University. Animals were accommodated for 1 week before the experiment. The study protocol was approved by The Institutional Animal Care and Use Committee, Hebei Medical University. All animal-handling procedures were performed according to the Guide for the Care and Use of Laboratory Animals of the National Institutes of Health and followed the guidelines of the Animal Welfare Act. Animals were randomized into the following three groups: control group (ten rats), CSE group (ten rats), and CSE + simvastatin $(\mathrm{CSE}+\mathrm{S})$ group (ten rats). Rats in the groups of CSE only or CSE $+\mathrm{S}$ were exposed to cigarette smoke (Shijiazhuang Cigarette creating $8 \mathrm{mg}$ tar, $0.8 \mathrm{mg}$ nicotine, and $10 \mathrm{mg}$ carbon monoxide) in a smoking device manufactured by Shijiazhuang Jinyang Science and Technology Inc. (model: JY-01, Shijiazhuang, People's Republic of China). Briefly, 20 cigarettes were burnt continuously and blown into a box together with oxygen, and animals were passively whole-body exposed to the cigarette smoke in the box for 1 hour each time, twice a day, 5 days a week for 16 weeks. Animals of CSE $+\mathrm{S}$ group were intra-gastrically administered simvastatin (MSD, Hangzhou, People's Republic of China) at a dose of $5 \mathrm{mg} / \mathrm{kg} /$ day, each day prior to the smoke exposure. ${ }^{14}$ The control rats were not treated with any reagent.

\section{BALF collection and analysis}

Animals were given an intraperitoneal injection of $10 \%$ chloral hydrate $(3 \mathrm{~mL} / \mathrm{kg})$. After trachea intubation, animals were sacrificed by bleeding at femoral artery. Three lobes of right lung were snap-frozen with liquid nitrogen and one lobe of the right lung was fixed with formaldehyde. Bronchoalveolar lavage was performed on the left lung, using a three-in/three-out pattern of main bronchial instillation and collection $3 \mathrm{~mL}$ saline (70\%-80\% recovery).

The total cell number in the BALF was counted with an erythrocytometer. The rest of BALF specimens were centrifuged at 1,000 rpm $\times 10$ minutes. Pelleted cells were 
resuspended with phosphate-buffered saline, and differentially counted by Wright-Giemsa staining. A total of 200 leukocytes was counted in each BALF sample, and the percentage of macrophage, neutrophil, and lymphocyte was calculated.

\section{Histological examination}

Air in the alveolar spaces was aspirated with a syringe before injecting $10 \%$ formalin in order to avoid alteration of lung structure. The fixed lung tissues were embedded in paraffin wax blocks and cut for hematoxylin and eosin staining. The hematoxylin and eosin stained slides were photographed under a light microscope (Olympus Corporation, Tokyo, Japan). Morphology of the lung tissue was observed and MLI was obtained by the following method. Cross lines were drawn in a field and the total number of alveolar septa at the intersection point of the two lines was counted. The total length of the cross lines divided by the number of intercepts gives the MLI for the region studied, that is, MLI = total length/number of alveolar septa. MLI indicates the average size of alveoli.

MAN was determined by the alveolar number per square millimeter under microscope, that is, $\mathrm{MAN}=$ alveolar number/ square millimeter. MAN is a parameter for density of alveoli.

BWT/D was obtained by measuring the bronchi with $<100 \mu \mathrm{m}$ circumference in size. At least eight bronchi were measured and the average of the ratio of wall thickness over diameter was calculated.

\section{Immunohistochemistry}

Expression of MMP-8, MMP-9, MMP-12, TIMP-1, and TIMP-4 in rat lung was assessed by immunohistochemistry. Briefly, paraffin embedded lung tissue slice was deparaffinized and rehydrated. Antigen was retrieved using sodium citrate and with heat-induced retrieval. After blocking with goat serum, antiMMPs or TIMPs antibodies at 1:200 dilution (all antibodies were purchased from Abcam, Shanghai, People's Republic of China - antiMMP-8 antibody: ab81286; antiMMP-9 antibody: ab76003; antiMMP-12 antibody: ab66157; antiTIMP-1 antibody: ab16412; antiTIMP-4 antibody: ab58425) were applied overnight at $4^{\circ} \mathrm{C}$. After horseradish peroxidase-conjugated second antibody was applied, expression of MMPs and TIMPs was visualized using a DAB detection kit. Images of MMP-8, MMP-9, MMP-12, TIMP-1, and TIMP-4 were obtained and photographed under microscope (Olympus Corporation).

\section{Real-time RT-PCR}

Total RNA was extracted from the snap-frozen rat lung tissues with Trizol reagent (SBS Genetech, Shanghai, People's Republic of China) following the manufacturer's instruction. After RNA quantification with ND-1000 spectrophotometer (NanoDrop, USA), $1 \mu \mathrm{g}$ total RNA was used for reverse transcription using high capacity reverse transcription kit (Baosheng Bio, Dalian, People's Republic of China). Quantitative real-time PCR was performed using primers/probe and reaction reagents, 7500 Gene Detection System (Applied Biosystem by Life Technology, Grand Island, NY, USA). $\beta$-Actin was used as internal control. Data were expressed as fold change versus control, using $2^{(-\Delta \Delta \mathrm{Ct})}$ method.

\section{Statistical analysis}

All data were analyzed by SPSS 13.0 statistical software, and presented as mean \pm standard deviation. One-way analysis of variance was used for comparison of multiple groups, and Dunnett's test was used for comparison of paired groups. It was considered statistically significant when $P<0.05$.

\section{Results General observation}

There were no differences in hair appearance, diet, activity, and reaction to surrounding environment before the experiment. At the early stage of the experiment, animals were in manic anxiety when they were exposed to cigarette smoke. At the late stage of the experiment, animals in the CSE and $\mathrm{CSE}+\mathrm{S}$ groups were less active, with shriveled hair, yellow teeth, and slow reaction and movement. No animal died during the CSE.

\section{Body weight alteration}

There was no difference in baseline body weight among the three groups $(P>0.05)$. After 16 weeks of smoke exposure, however, body weight was significantly reduced in the CSE and CSE $+\mathrm{S}$ groups compared to the control rats (445 \pm 12 of CSE only, $446 \pm 23$ of CSE $+\mathrm{S}$ group vs $503 \pm 15 \mathrm{~g}$ of control, $P<0.01)$. Simvastatin could not prevent smoke-induced weight loss ( $P>0.05$ compared to control group).

\section{Histopathological alteration}

MLI and BWT/D were significantly increased in the CSE group compared to that in control group (MLI: $34.6 \pm 2.0$ of CSE vs $24.0 \pm 1.7 \mu \mathrm{m}$ of control; BWT/D: $0.250 \pm 0.062$ of CSE vs $0.160 \pm 0.034$ of control, $P<0.01$ ). In contrast, MAN was significantly decreased in the CSE group than that in the control group $\left(13.5 \pm 2.0\right.$ of CSE vs $21.5 \pm 2.0 \mathrm{~N} / \mu \mathrm{m}^{2}$ of control, $P<0.01)$. Simvastatin slightly but not significantly blocked alteration of MLI, BWT/D, and MAN in response to cigarette smoke stimulation (MLI: $33.4 \pm 1.4 \mu \mathrm{m}$; BWT/D: $0.220 \pm 0.052$; MAN: $15.5 \pm 2.5 \mathrm{~N} / \mu \mathrm{m}^{2}, P>0.05$, Figure 1). 
A

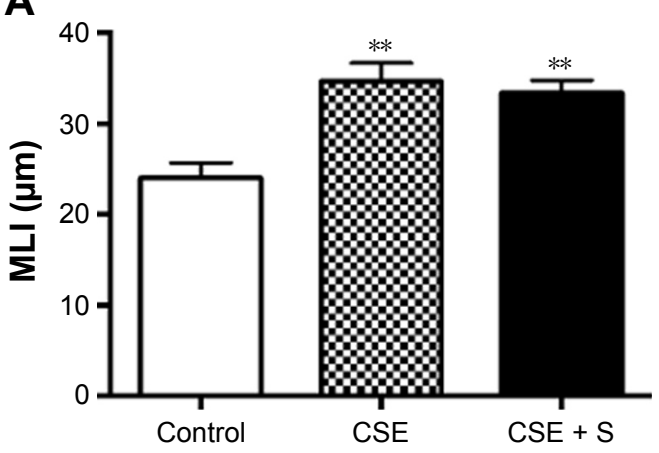

B

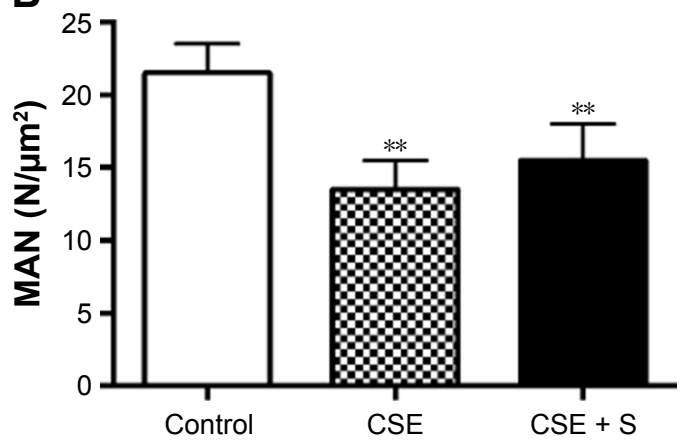

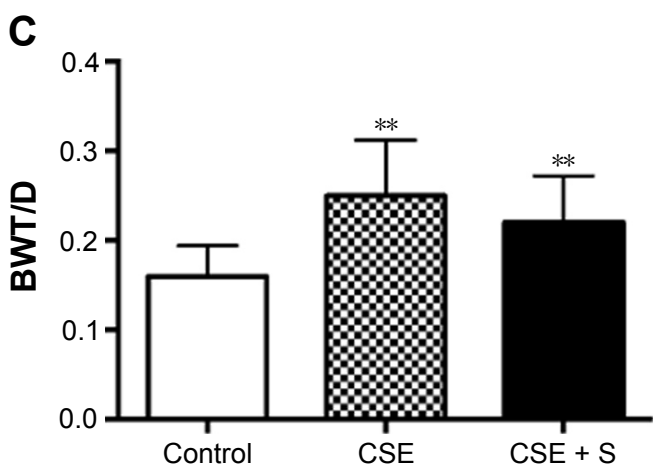

Figure I Histological parameters of emphysema model.

Notes: Paraffin embedded lung tissue slides were stained with hematoxylin and eosin. (A) MLI, (B) MAN, and (C) BWT/D. **P $<0.01$ compared to control group.

Abbreviations: BWT/D, bronchial wall thickness over diameter; CSE, cigarette smoke exposure group; MLI, mean linear intercept; MAN, mean alveolar number; S, simvastatin.

\section{BALF total and differential cell count}

There was no difference in BALF recovery volume among control, $\mathrm{CSE}$, and $\mathrm{CSE}+\mathrm{S}$ groups $(P>0.05)$. As expected, the number of total white blood cells was significantly increased in the BALF of smoking group $\left(3.3 \pm 2.5 \times 10^{9}\right.$ cells $/ \mathrm{L}$ vs $1.1 \pm 1.3 \times 10^{9}$ cells/L of control, $P<0.01$ ), and it was significantly reduced in the rats treated with simvastatin $\left(2.3 \pm 2.1 \times 10^{9}\right.$ cells/L, $P<0.01$, Figure $2 \mathrm{~A}$ ). Moreover, differential count of neutrophils, macrophages, and lymphocytes showed that CSE resulted in significantly increased accumulation of neutrophils and macrophages (neutrophils: $14.5 \% \pm 1.3 \%$ of CSE group vs $9.1 \% \pm 1.5 \%$ of control; macrophage: $91 \% \pm 3 \%$ of CSE group vs $87 \% \pm 2 \%$ of control, $P<0.05$ ) but with a decrease in lymphocytes in the bronchial alveolar lavage $(7.0 \% \pm 2.9 \%$ of CSE group vs $9.3 \% \pm 1.2 \%$ of control, $P<0.01)$. Simvastatin significantly reduced neutrophils $(12.9 \% \pm 2.0 \%, P<0.05)$ in the BALF, but had no effect on macrophage $(89 \% \pm 1.6 \%)$ or lymphocytes $(6.4 \% \pm 2.3 \%$, Figure $2 \mathrm{~B})$.
A

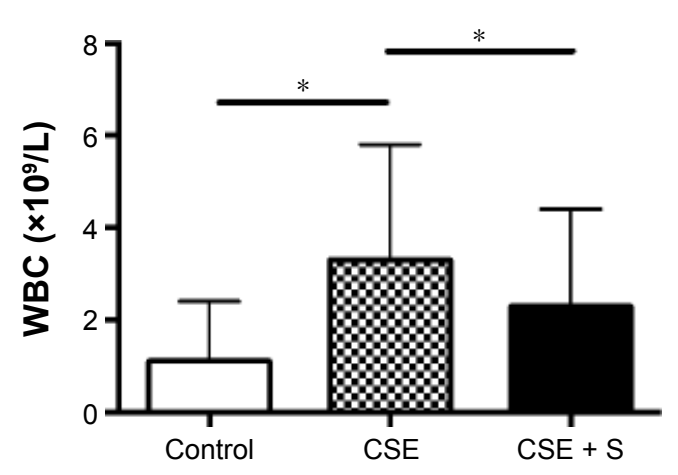

B

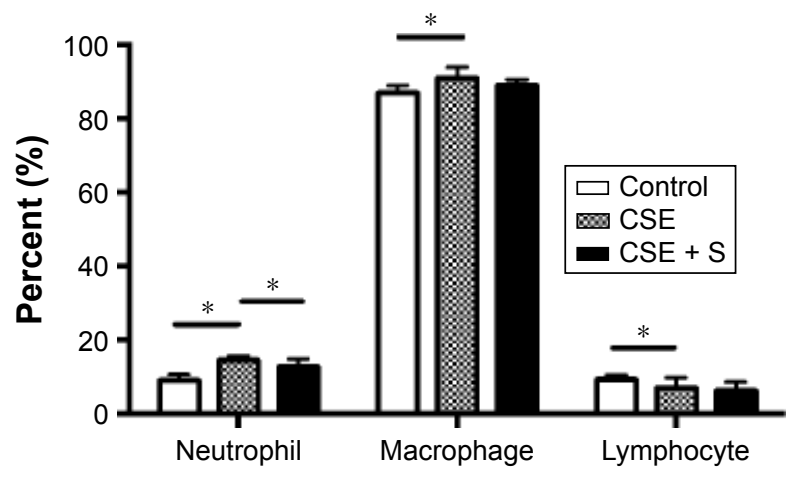

Figure 2 BALF cell count.

Notes: (A) Total cell number in the three groups. Vertical axis: total cell number; horizontal axis: treatment groups. (B) Differential cell count. Vertical axis: percent of each cell type (\%); horizontal axis: cell types. $* P<0.05$.

Abbreviations: BALF, bronchial alveolar lavage fluid; CSE, cigarette smoke exposure group; WBC, white blood cell; S, simvastatin. 
A

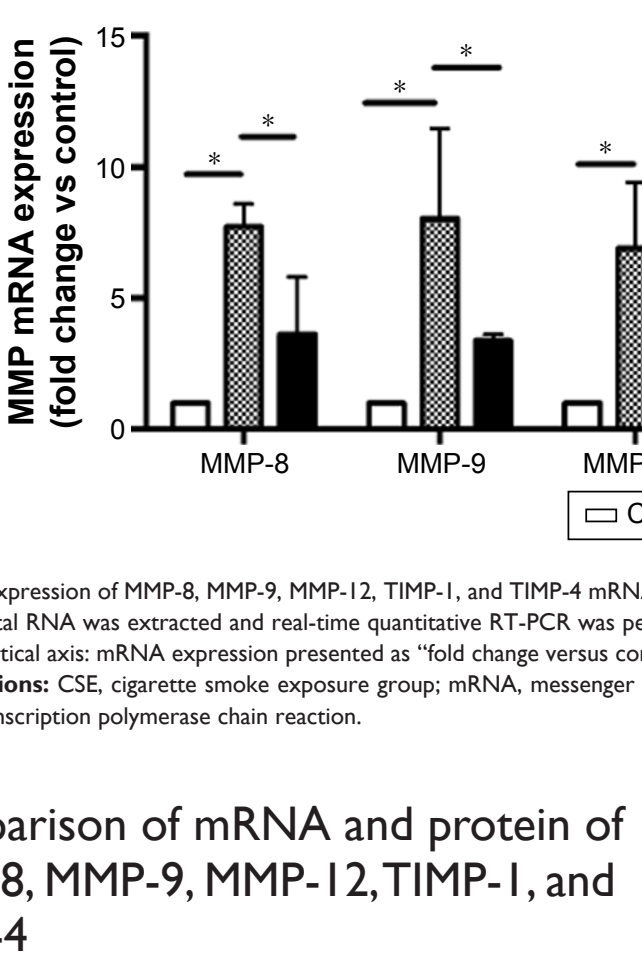

\section{Discussion}

COPD is characterized by chronic airway inflammation and irreversible airway obstruction in response to irritant gas or particulates exposure. ${ }^{15}$ The current study demonstrated that simvastatin decreased accumulation of inflammatory cells in the airways of cigarette smoke-induced COPD rat models. Furthermore, simvastatin decreased upregulation of MMP-8 and -9, but had no effect on MMP-12, TIMP-1, and TIMP-4 mRNA and protein in the lung tissues of the rats exposed to cigarette smoke. However, simvastatin could not reverse or block the alteration of MLI, MAN, or BWT/D in response
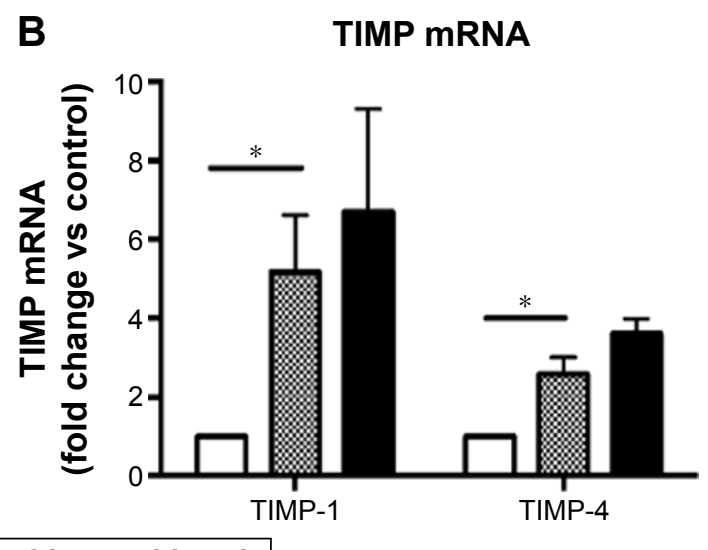

\begin{abstract}
Notes: Total RNA was extracted and real-time quantitative RT-PCR was performed. (A) Expression of MMP-8, -9, and MMP-I2 mRNA. (B) Expression of TIMP-I and -4 versus control;" horizontal axis: MMP or TIMP. $* P<0.05$ Abbreviations: CSE, cigarette smoke exposure group; mRNA, messenger RNA; MMP, matrix metalloproteinase; TIMP, tissue inhibitor of MMP; S, simvastatin; RT-PCR,
reverse transcription polymerase chain reaction.
\end{abstract}

\section{Expression of MMP-8, MMP-9, MMP-12, TIMP-1, and TIMP-4 mRNA was significantly upregulated in the CSE group compared to that in control group $(P<0.01)$. Simvas- tatin significantly blocked upregulation of MMP-8 and -9 in response to CSE $(P<0.01)$, but had no effect on MMP-12, TIMP-1, and TIMP-4 mRNA ( $P>0.05$, Figure 3 ). Consistent with the effect on mRNA expression of MMPs and TIMPs, CSE resulted in a significant stimulation of MMP-8 and -9 protein synthesis (Figure $4 \mathrm{~B}$ and $\mathrm{E}$ ), but had no significant effect on MMP-12 (Figure 4H), TIMP-1 (Figure 4K), and TIMP-4 (Figure 4N) protein release. Simvastatin significantly blocked cigarette smoke-induced protein synthesis of MMP-8 (Figure 4C) and -9 (Figure 4F), but had no significant effect on MMP-12 (Figure 4I). Moreover, simvastatin significantly stimulated TIMP-1 (Figure 4L) and -4 (Figure 4O) protein synthesis even in the presence of cigarette smoke. \\ Comparison of $m R N A$ and protein of MMP-8, MMP-9, MMP-I2, TIMP-I, and TIMP-4} to cigarette smoke stimulation. These findings suggested that simvastatin may modulate airway inflammation and part of MMP (MMP-8 and -9) release.

Chronic airway inflammation is believed to play a major role in the development of COPD. Cigarette smoke contains more than a 1,000 chemicals that stimulate the airway cells to release inflammatory cytokines, such as interleukin (IL)-1 $\beta,-6$ and $-8,{ }^{16-18}$ and cause airway injury. ${ }^{19}$ Under the effect of these inflammatory cytokines, neutrophils and macrophages migrate to the site of injury and result in further tissue injury and remodeling. Consistent with this concept, the current study demonstrated that CSE in the rats resulted in accumulation of neutrophils and macrophages and that there is significant damage of alveolar structure (MLI increase and MAN decrease) and airway tissue remodeling (altered BWT/D).

Proteases have been believed to play a major role in the pathogenesis of COPD and emphysema. In this context, mice deficient in the macrophage elastase MMP-12 have been reported to be resistant to the development of cigarette smoke-induced emphysema; ${ }^{20}$ upregulation of MMP-9 in the lungs has also been reported to be associated with emphysema not only in experimental animal models ${ }^{21,22}$ but also clinical patients. ${ }^{23}$

However, expression of MMPs in normal lung is very low or undetectable. In the presence of inflammation or irritants, including cigarette smoke, however, expression of MMPs is dramatically increased and readily detectable in a variety of lung diseases, including COPD and emphysema. In the cigarette smoke-induced COPD animal model, cigarette smoke may stimulate MMPs directly or indirectly through inflammatory cytokines, such as IL-1 $\beta$ and tumor 

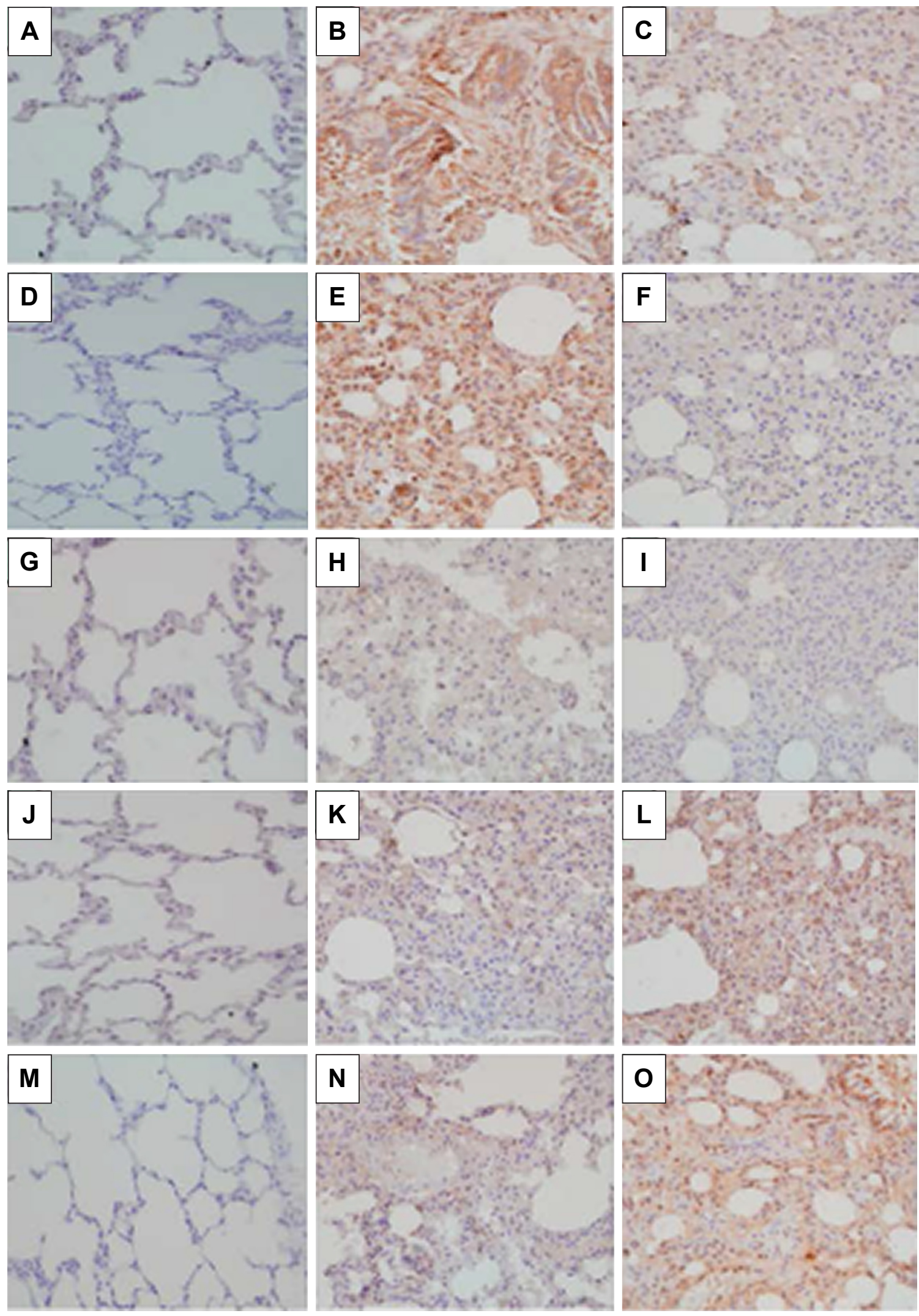

Figure 4 Effect of simvastatin on protein synthesis of MMPs and TIMPs.

Notes: Lung tissue section was immunostained for MMP-8, MMP-9, MMP-I2, TIMP-I, and TIMP-4. (A-C) MMP-8; (D-F) MMP-9; (G-I) MMP-I2; (J-L) TIMP-I; and (M-O) TIMP-4. (A, D, G, J, M) Control animal lungs; (B, E, H, K, N) cigarette smoke exposure animal lungs; and (C, F, I, L, O) animals exposed to cigarette smoke plus simvastatin treatment. Data presented were one representative image data. Magnification: 200X.

Abbreviations: MMP, matrix metalloproteinase; TIMP, tissue inhibitor of MMP. 
necrosis factor- $\alpha$. In this context, MMP-1 (collagenase 1) and -8 (collagenase 2 ) have been reported to be upregulated in COPD lungs and epithelial cells. ${ }^{24}$ Consistent with previous reports, the current study demonstrated that expression of MMP-8, -9, and -12 mRNA was significantly upregulated in the model of cigarette smoke-induced COPD. In addition, expression of TIMP-1 and -4 mRNA was also increased in the COPD model. However, the fold of TIMP-1 and -4 increase (two- to fivefold) was less than that of MMP-8, -9, and -12 ( $>7$-fold). Furthermore, simvastatin not only significantly blocked cigarette smoke-induced MMP- 8 and -9 protein synthesis, but also significantly stimulated TIMP-1 and -4 protein synthesis in the presence of cigarette smoke, suggesting that imbalance of MMPs versus TIMPs may play a role in the pathogenesis of COPD and emphysema in response to CSE, and that simvastatin blocks development of COPD and emphysema, at least partially, through modulating protein synthesis of MMP-8, MMP-9, TIMP-1, and TIMP-4.

Statins were originally developed for their cholesterollowering properties and efficacy in the cardiovascular disease. However, previous studies indicated that statins not only have an effect of immunomodulation, antioxidant, antithormbogenic and vascular actions, ${ }^{25,26}$ but also decrease the expression of MMPs in vascular cells and macrophages in vitro. ${ }^{13,27}$ Consistent with this effect on MMPs, statins have been reported to inhibit the development of emphysema in experimental animal models. In this regard, Lee et $\mathrm{a}^{28}$ found that simvastatin inhibited lung parenchymal destruction and MMP-9 expression in a rat model of cigarette smoking-induced emphysema. Moreover, in a mouse model of elastase-induced emphysema, it had been reported that simvastatin reduced mRNA expression for tumor necrosis factor- $\alpha$ and MMP-12 in the whole lung. ${ }^{29}$ The current study extends these observations and further demonstrated that simvastatin significantly decreased alveolar accumulation of neutrophils and expression of MMP-8 and -9 in the whole lung. However, cigarette smoke had no significant effect on MMP-12 protein synthesis and simvastatin could not significantly decrease MMP-12 expression in response to CSE. Moreover, simvastatin had no effect on alteration of MLI, MAN, and BWT/D, suggesting simvastatin could significantly inhibit airway inflammation and MMP-8 and -9 release, but may not block proteinase-induced alteration of lung structures, and, thus, may have no direct effect on tissue repair and remodeling.

Taken together, the current study demonstrates that simvastatin can inhibit accumulation of neutrophils in the airways, and decrease mRNA expression and protein synthesis of MMP-8 and -9 in rat lungs in response to CSE. Simvastatin, however, has no significant effect on lung tissue repair and remodeling.

\section{Disclosure}

The authors report no conflicts of interest in this work.

\section{References}

1. Rennard SI, Drummond MB. Early chronic obstructive pulmonary disease: definition, assessment, and prevention. Lancet. 2015;385(9979): $1778-1788$.

2. Rennard SI. Overview of causes of COPD. New understanding of pathogenesis and mechanisms can guide future therapy. Postgrad Med. 2002;111(6):28-30, 33-34, 37-38.

3. Heulens N, Korf H, Cielen N. Vitamin D deficiency exacerbates COPD-like characteristics in the lungs of cigarette smoke-exposed mice. Respir Res. 2015;16:110.

4. Kamiide Y, Inomata N, Furuya M, Yada T. Ghrelin ameliorates catabolic conditions and respiratory dysfunction in a chronic obstructive pulmonary disease model of chronic cigarette smoke-exposed rats. Eur J Pharmacol. 2015;755:88-94.

5. Wang Y, Jiang X, Zhang L, Wang L, Li Z, Sun W. Simvastatin mitigates functional and structural impairment of lung and right ventricle in a rat model of cigarette smoke-induced COPD. Int J Clin Exp Pathol. 2014; 7(12):8553-8562.

6. Parks WC, Shapiro SD. Matrix metalloproteinases in lung biology. Respir Res. 2001;2(1):10-19.

7. Kamio K, Liu XD, Sugiura H. Statins inhibit matrix metalloproteinase release from human lung fibroblasts. Eur Respir J. 2010;35(3): 637-646.

8. Jouneau S, Khorasani N, De Souza P, et al. EMMPRIN (CD147) regulation of MMP-9 in bronchial epithelial cells in COPD. Respirology. 2011;16(4):705-712.

9. Ishida W, Kajiwara T, Ishii M. Decrease in mortality rate of chronic obstructive pulmonary disease (COPD) with statin use: a populationbased analysis in Japan. Tohoku J Exp Med. 2007;212(3):265-273.

10. Søyseth V, Brekke PH, Smith P, Omland T. Statin use is associated with reduced mortality in COPD. Eur Respir J. 2007;29(2):279-283.

11. Hothersall E, McSharry C, Thomson NC. Potential therapeutic role for statins in respiratory disease. Thorax. 2006;61(8):729-734.

12. Bellosta S, Via D, Canavesi M, et al. HMG-CoA reductase inhibitors reduce MMP-9 secretion by macrophages. Arterioscler Thromb Vasc Biol. 1998;18(11):1671-1678.

13. Ikeda U, Shimpo M, Ohki R, et al. Fluvastatin inhibits matrix metalloproteinase-1 expression in human vascular endothelial cells. Hypertension. 2000;36(3):325-329.

14. Menard G, Turmel V, Bissonnette EY. Serotonin modulates the cytokine network in the lung: involvement of prostaglandin E2. Clin Exp Immunol. 2007;150(2):340-348.

15. Marin L, Colombo P, Bebawy M, Young PM, Traini D. Chronic obstructive pulmonary disease: patho-physiology, current methods of treatment and the potential for simvastatin in disease management. Expert Opin Drug Deliv. 2011;8(9):1205-1220.

16. Moon HG, Zheng Y, An CH, Kim YK, Jin Y. CCN1 secretion induced by cigarette smoking extracts augments IL-8 release from bronchial epithelial cells. PLoS One. 2013;8(7):e68199.

17. Wang H, Yang T, Shen Y, et al. Ghrelin inhibits interleukin-6 production induced by cigarette smoke extract in the bronchial epithelial cell via NF-kappaB pathway. Inflammation. 2016;39(1):190-198.

18. Rusznak C, Mills PR, Devalia JL, Sapsford RJ, Davies RJ, Lozewicz S. Effect of cigarette smoke on the permeability and IL-1beta and sICAM-1 release from cultured human bronchial epithelial cells of never-smokers, smokers, and patients with chronic obstructive pulmonary disease. Am J Respir Cell Mol Biol. 2000;23(4):530-536. 
19. Goldkorn T, Filosto S, Chung S. Lung injury and lung cancer caused by cigarette smoke-induced oxidative stress: molecular mechanisms and therapeutic opportunities involving the ceramide-generating machinery and epidermal growth factor receptor. Antioxid Redox Signal. 2014;21(15):2149-2174.

20. Hautamaki RD, Kobayashi DK, Senior RM, Shapiro SD. Requirement for macrophage elastase for cigarette smoke-induced emphysema in mice. Science. 1997;277(5334):2002-2004.

21. Selman M, Cisneros-Lira J, Gaxiola M, et al. Matrix metalloproteinases inhibition attenuates tobacco smoke-induced emphysema in Guinea pigs. Chest. 2003;123(5):1633-1641.

22. Lappalainen U, Whitsett JA, Wert SE, Tichelaar JW, Bry K. Interleukin1beta causes pulmonary inflammation, emphysema, and airway remodeling in the adult murine lung. Am J Respir Cell Mol Biol. 2005;32(4): 311-318.

23. Russell RE, Culpitt SV, DeMatos C, et al. Release and activity of matrix metalloproteinase- 9 and tissue inhibitor of metalloproteinase- 1 by alveolar macrophages from patients with chronic obstructive pulmonary disease. Am J Respir Cell Mol Biol. 2002;26(5):602-609.
24. Segura-Valdez L, Pardo A, Gaxiola M, Uhal BD, Becerril C, Selman M. Upregulation of gelatinases A and B, collagenases 1 and 2, and increased parenchymal cell death in COPD. Chest. 2000;117(3):684-694.

25. Bonetti PO, Lerman LO, Napoli C, Lerman A. Statin effects beyond lipid lowering - are they clinically relevant? Eur Heart J. 2003;24(3): 225-248.

26. Greenwood J, Steinman L, Zamvil SS. Statin therapy and autoimmune disease: from protein prenylation to immunomodulation. Nat Rev Immunol. 2006;6(5):358-370.

27. Luan Z, Chase AJ, Newby AC. Statins inhibit secretion of metalloproteinases-1, $-2,-3$, and -9 from vascular smooth muscle cells and macrophages. Arterioscler Thromb Vasc Biol. 2003;23(5):769-775.

28. Lee JH, Lee DS, Kim EK. Simvastatin inhibits cigarette smokinginduced emphysema and pulmonary hypertension in rat lungs. $\mathrm{Am} \mathrm{J}$ Respir Crit Care Med. 2005;172(8):987-993.

29. Takahashi S, Nakamura H, Seki M. Reversal of elastase-induced pulmonary emphysema and promotion of alveolar epithelial cell proliferation by simvastatin in mice. Am J Physiol Lung Cell Mol Physiol. 2008;294(5):L882-L890.

\section{Publish your work in this journal}

The International Journal of COPD is an international, peer-reviewed journal of therapeutics and pharmacology focusing on concise rapid reporting of clinical studies and reviews in COPD. Special focus is given to the pathophysiological processes underlying the disease, intervention programs, patient focused education, and self management protocols.

\section{Dovepress}

This journal is indexed on PubMed Central, MedLine and CAS. The manuscript management system is completely online and includes a very quick and fair peer-review system, which is all easy to use. Visit http://www.dovepress.com/testimonials.php to read real quotes from published authors.

Submit your manuscript here: http://www.dovepress.com/international-journal-of-chronic-obstructive-pulmonary-disease-journal 